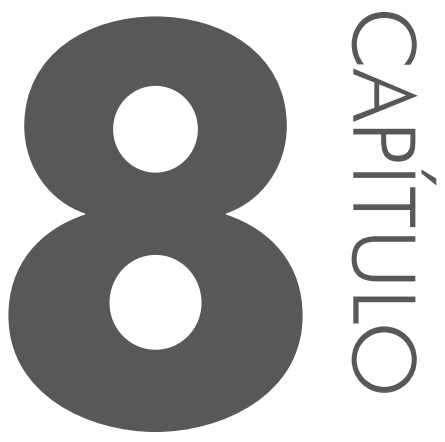

\title{
PROPOSTA PARA ANÁLISE DAS DINÂNICAS EROSIVAS DE UMA VOÇOROCA LOCALIZADA NOS BAIRROS NOVA ITUIUTABA NA CIDADE DE ITUIUTABA-MG
}

Taison Luiz de Paula Braghiroli Rildo Aparecido Costa

Resumo: Este trabalho teve por objetivo apresentar uma proposta metodológica na busca de compreender as dinâmicas envolvidas no processo de voçorocamento em uma área específica do município de Ituiutaba-MG, neste caso, na voçoroca presente nos bairros Nova Ituiutaba e, para isso, foram utilizados embasamentos bibliográficos que abordam a temática proposta. O método das 
estacas adaptado por Guerra (1996) e a análise de solo indicada pela Embrapa (1997) formam a base da proposta apresentada. O estaqueamento será utilizado no monitoramento de erosão da borda da voçoroca, sendo as estacas utilizadas como referências na mensuração de erosão linear, ou seja, as estacas serão fixadas no solo em torno da feição para calcular a taxa de solo erodido. Com relação à análise de solo, será feita uma análise física das amostras coletadas, identificando elementos como a espessura e o arranjo dos horizontes, a transição entre eles, a textura, a plasticidade, a estrutura, a porosidade, a cerosidade e a consistência, além da análise granulométrica para identificação da porcentagem de areia, silte e argila nas amostras. Por se tratar de uma pesquisa em andamento ainda não é possível apresentar dados concretos sobre essas dinâmicas no referido recorte de estudo.

Palavras-chave: Voçoroca. Monitoramento. Solo. Ituiutaba-MG.

Abstract: This study aimed to present a methodological approach in seeking to understand the dynamics involved in gully process in a specific area the city of Ituiutaba-MG, in this case in this gully in New Ituiutaba neighborhoods and it was used bibliographic emplacements adressing the proposed theme. The method of cuttings, adapted by Guerra (1996) and soil analysis indicated by Embrapa (1997) were the basis of the proposal. The piling will be used in erosion monitoring the edge of the gully, and the stakes used as references in the linear erosion measurement, ie, the pegs are fixed in the soil surrounding the feature to calculate the rate eroded soil. With respect to soil analysis, it will be a physical analysis of samples collected identifying elements such as the thickness and arrangement of horizons, the transition between them, texture, plasticity, structure, porosity, and waxy consistency, in addition to granulometric analysis to identify the percentage of sand, silt and clay in the samples. These methodologies will be applied in order to understand the dynamics of active erosion in the gully. Since this is an ongoing research still can not provide specific data on these dynamics in the study clipping.

Keywords: Gully. Monitoring. Soil. Ituiutaba-MG.

\section{INTRODUC̣ÃO}

Com o aumento da agricultura nos solos tropicais por meio de técnicas cada vez mais agressivas e da criação de gados, foi possível perceber que a supressão da vegetação era/é uma regra para a implantação de espaços agrários, resultando na perda da fauna e da flora, na poluição de mananciais e lençóis d'água e em processos erosivos, sendo este último impacto o que será considerado neste estudo.

O processo de erosão é um fenômeno natural que existe há milhões de anos antecedendo o aparecimento do homem na Terra e tem grande impacto na formação do modelado da superfície terrestre, dos solos e das rochas sedimentares, ou seja, os processos erosivos são responsáveis pela esculturação do relevo e de grande importância para a evolução das formas superficiais. Esse processo age 
na remoção, no transporte e na deposição de sedimentos resultantes do intemperismo, porém tem sido acelerado devido a má utilização e ocupação do relevo o que, consequentemente, resultam em formas degradativas observadas nas mais diversas paisagens.

Faz-se por meio da história uma observação que a expansão das atividades ligadas às práticas agrícolas e à pecuária no território brasileiro tem demonstrado, por meio de estudos científicos, que as aplicações de técnicas de conservação e manutenção dos solos tropicais ainda não estão sendo aplicadas por todo o território. Mesmo nos lugares onde essas técnicas existem e são aplicadas, algumas vezes elas não são eficazes devido à falta de monitoração e manutenção. As técnicas de conservação das estradas rurais que envolvem o direcionamento das águas pluviais, o controle de sedimentos por meio da construção de bacias de contenção, dos terraços em curvas de nível, o levantamento de estradas rurais, a quebra de taludes e a construção de canais de drenagem, são realizadas para se evitar processos erosivos, no entanto, essas técnicas de conservação necessitam de manutenção, o que muitas vezes não ocorre e os problemas erosivos voltam a ocorrer.

$\mathrm{Na}$ Microrregião Geográfica de Ituiutaba, situada no Triângulo Mineiro, houve um rápido processo de substituição do Cerrado, mata nativa, por cultivos agrícolas (principalmente o de cana-de-açúcar) e por pastagens plantadas, gerando uma mudança gradativa na paisagem das vertentes. Além dessas atividades agropecuárias, outro elemento que tem provocado mudanças na forma do relevo da região é o crescimento das cidades, em um curto espaço de tempo, por meio da construção de pavimentação e da expansão de loteamentos e conjuntos habitacionais, o que muitas vezes atinge áreas de cabeceiras de drenagem em anfiteatro, degradando assim formas de relevo onde se encontram as nascentes.

Esses são fatores que contribuem para a concentração de águas pluviais e a intensificação dos processos erosivos lineares e se agravam principalmente quando esse processo ocorre em áreas de cabeceiras de drenagem em anfiteatro com a presença de solos arenosos e profundos, podendo esculturar a vertente e originar formas erosivas do tipo voçoroca.

A partir do exposto, o presente trabalho tem como objetivo apresentar metodologias para o estudo das dinâmicas do processo de voçorocamento em uma área do município de Ituiutaba-MG. Para alcançar o objetivo proposto, serão utilizados, como procedimento metodológico, um levantamento bibliográfico que aborde a temática de processos erosivos e voçorocas, em especial a metodologia de monitoramento proposta por Guerra (1996) e Francisco (2011) e a análise morfológica e granulométrica do solo com base no manual de métodos de análise da Embrapa (1997).

É importante salientar que a pesquisa está em andamento e, por esse motivo, ainda não é possível apresentar dados concretos sobre as dinâmicas erosivas do referido recorte de estudo. 


\section{CARACTERIZAC̣ÃO DA ÁREA DE ESTUDO}

O presente trabalho origina-se de um estudo no município de Ituiutaba-MG (ver Figura 1), situado na mesorregião do Triângulo Mineiro e Alto Paranaíba, cuja sede se encontra nas coordenadas geográficas $18^{\circ} 56^{\prime} 28^{\prime \prime}$ de latitude Sul e 49 $27^{\prime} 47^{\prime \prime}$ de longitude Oeste, com população total de 97.171 habitantes e uma área territorial de $2.598,046 \mathrm{~km}^{2}$, segundo a Prefeitura Municipal. Tratando-se do relevo, Baccaro (1991) salienta que grande parte do município está inserido em uma área de relevo medianamente dissecado com formas convexas e vertentes entre 3 e $15^{\circ}$ de declividade.

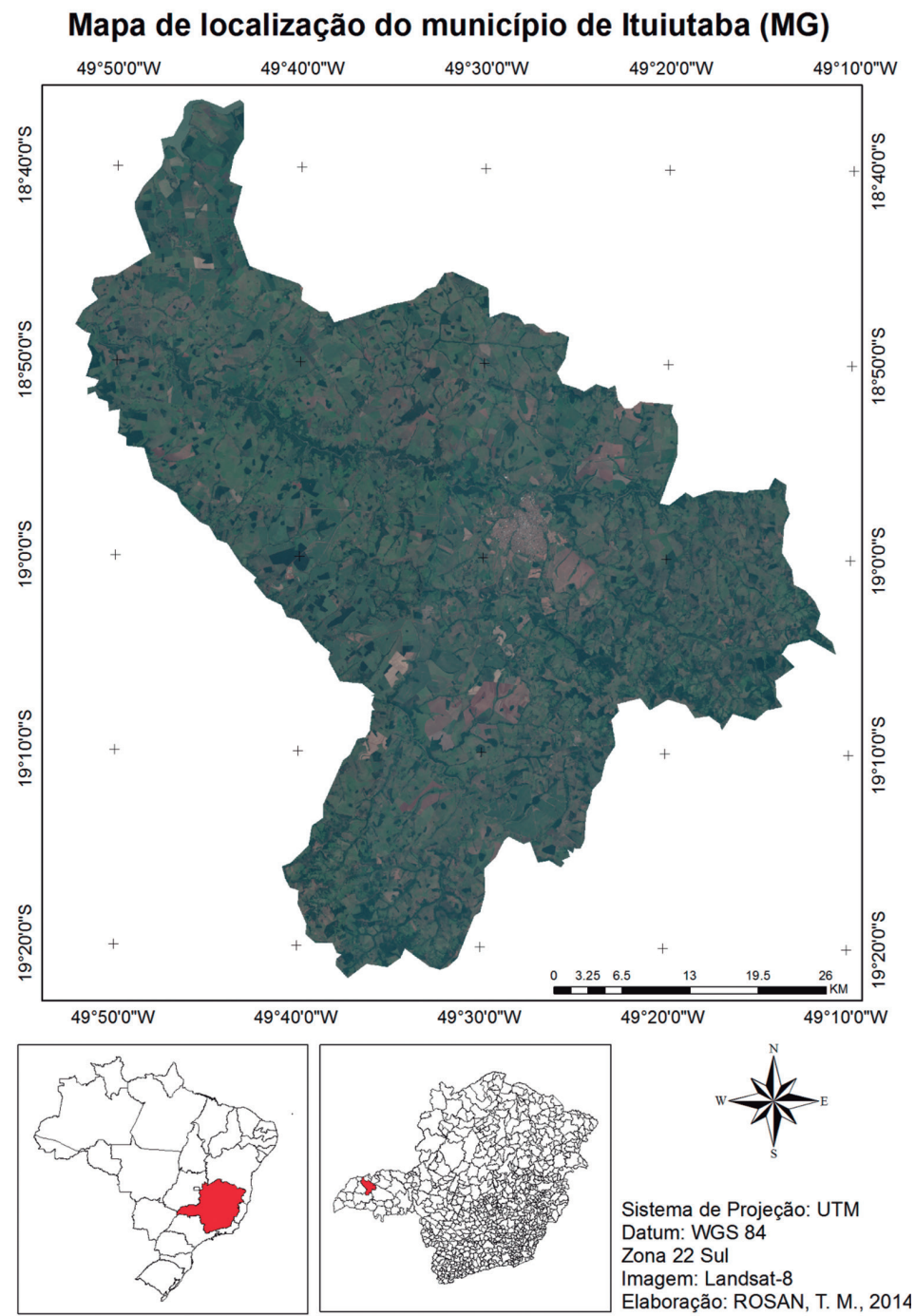

Figura 1. Localização do município de ltuiutaba-MG. Fonte: Rosan (2014). 
O clima predominante na região estudada é o regime tropical que é caracterizado pelo verão úmido e quente e o inverno seco e ameno. Nesse regime, o principal fenômeno é a Zona de Convergência do Atlântico Sul observada tanto nos dados climatológicos de precipitação, quanto nas imagens de satélite meteorológico (ABREU, 2000).

Os bairros Nova Ituiutaba I, II, III e IV estão sendo construídos por meio das políticas públicas habitacionais brasileiras, com o objetivo principal de diminuir a carência habitacional, especialmente das famílias de baixa renda. A localização desses bairros está descontínua na malha urbana do município e as habitações foram construídas em toda a vertente, impermeabilizando grande parte dela.

Outro fator que deve ser levado em consideração na área de estudo é que não existe um sistema adequado de captação das águas pluviais, o que obriga essa água a ganhar velocidade no sentido da montante para a jusante da vertente, acelerando ainda mais os processos erosivos na área.

\section{O PROCESSO EROSIVO E SUA FUNDAMENTAC̣ÃO NAS TEORIAS GEOMORFOLÓGICAS}

A erosão não se trata apenas de um processo degradativo do solo, pois este também faz parte da dinâmica natural de esculturação do relevo. Para Lepsch (2002, p. 149) os "[...] rios, os ventos, as geleiras e as enxurradas das chuvas deslocam, transportam e depositam continuamente as partículas do solo. Este fenômeno é denominado erosão geológica ou natural". O processo de erosão é um fenômeno que existe há milhões de anos, antecedendo o aparecimento do homem na Terra, e tem grande impacto na formação do modelado da superfície terrestre, dos solos e das rochas sedimentares (WEILL; NETO, 2007). Portanto, o termo erosão se refere a um: "Conjunto de processos que atuam na superfície terrestre, levando à remoção de materiais minerais e rochas decompostas. Quando a água constitui o agente essencial, o processo de dissolução torna-se muito importante. Os principais agentes de remoção física e transporte durante os processos de erosão são os seguintes: eólico, fluvial, marinho e glacial” (SUGUIO, 1998, p. 276).

No início do processo erosivo, segundo o trabalho de Guerra (1999), há a erosão por salpico, na qual o impacto das gotas de chuva desagrega as partículas do solo em tamanhos menores ocorrendo o transporte por esse salpicamento, cujo teor da matéria orgânica, textura, densidade, porosidade e estrutura, bem como características das encostas, da cobertura vegetal, da erosividade da chuva e do uso da terra interferem de forma direta ou indireta na quebra dos agregados.

Essas partículas desagregadas podem preencher os poros do solo diminuindo a porosidade e, consequentemente, a infiltração nesse solo, e favorecendo o escoamento superficial que pode atingir altas velocidades, capazes de retirar e 
transportar sedimentos (GUERRA, 1999). Esse escoamento pode ser classificado como difuso, linear e laminar, sendo que no escoamento difuso a água percorre filetes anastomosados no terreno com cobertura vegetal.

O escoamento linear é gerado quando as águas pluviais se concentram em canais, já o escoamento laminar é caracterizado pela falta de concentração dessas águas em canais, ou seja, ela escoa em forma de lâmina sobre uma superfície desprovida de vegetação (ROSSATO et al., 2003). Portanto, no momento em que o solo está saturado a água tende a se deslocar para áreas a jusante promovendo a erosão laminar (GUERRA, 1999).

Relacionado ao escoamento subsuperficial, Ab'Saber (1968) diz que a dinâmica de erosão subterrânea não pode ser medida pela observação da paisagem superficial, sendo que:

[...] antes mesmo que as lesões apareçam, por grandes faixas na paisagem superficial já, em subsuperfície, os processos estão sendo preparados pela percolação linear e concentrada dos lençóis d' água subsuperficiais. E, quando as ravinas se expandem e se definem na paisagem das vertentes, o processo já caminhou muito além do que se possa deduzir pela simples observação estática da morfologia dos buracões [...] Neste sentido, toda boçoroca é uma lesão aberta e um processo em plena atividade (AB'SABER, 1968, p. 268).

O processo de erosão interna provocado pela existência de dutos de escoamento subsuperficial pode agravar o processo de voçorocamento. Segundo Salomão (1999), a erosão por dutos (piping) acarreta a retirada de partículas do interior do solo ocasionando a formação de canais que evoluem no sentido contrário ao fluxo de água e podem gerar desabamentos que podem alargar a voçoroca ou criar novas ramificações.

Para Augustin e Aranha (2006), esse fenômeno do piping pode estar relacionado ao comportamento sazonal do nível freático, à existência de raízes decompostas ou em decomposição de túneis biogênicos causados por insetos e roedores, como também à ocorrência de horizontes pedológicos pouco permeáveis.

Segundo Fushimi (2012), em áreas onde há vulnerabilidades geológicas e pedológicas ou condicionadas pelo uso da terra, o fluxo de água pode ser linear, concentrado, aumentando a velocidade dessa água e, consequentemente, aumentando a profundidade. A partir disso, a concentração de sedimentos atrita com o fundo dos pequenos canais formados, dando origem, posteriormente, às ravinas, que, segundo Oliveira (1999), "seriam canais criados pela ação do escoamento superficial; e voçorocas, canais esculpidos pelo afloramento do lençol freático".

Com o aprofundamento das ravinas, interceptando o nível freático, pode-se observar a presença de inúmeros processos erosivos resultantes da ação concomi- 
tante das águas superficiais e subsuperficias em que as ravinas, atingindo grandes dimensões, iniciam o processo de voçorocamento (SALOMÃO, 1999).

Para Rossato (2003), as origens de algumas voçorocas podem ocorrer pelo aprofundamento de ravinas ou pelo escoamento subsuperficial: “[...] o qual dá origem a dutos (pipes). São relativamente permanentes nas encostas. Têm paredes laterais íngremes, em geral, fundo chato, ocorrendo fluxo de água no seu interior durante os períodos chuvosos. Ao aprofundarem seus canais, as voçorocas atingem o lençol freático. Constituem um processo de erosão acelerada e de instabilidade nas paisagens" (ROSSATO, 2003, p. 245).

Ainda, segundo Salomão (2009), as voçorocas são caracterizadas pelo alto poder destrutivo, sendo um local de ocorrência de diversos fenômenos, como solapamentos, erosões internas, erosões superficiais, desabamentos e escorregamentos e, dessa forma, as voçorocas apresentam ameaças à estabilidade do solo e riscos à população que vive próxima a elas, devido a sua dinâmica catastrófica e muitas vezes imprevisível (FRANCISCO, 2011).

Furlani (1980) define a morfologia das voçorocas como circulares e lineares, sendo as circulares caracterizadas por serem profundas e alongadas, dilatadas a jusante e afuniladas a jusante; já as lineares são caracterizadas por incisões estreitas geradas pelo aprofundamento e alargamento das ravinas, mostrando-se pouco profundas, estreitas e de grande comprimento.

Nesse sentido, a Ciência Geográfica pode buscar a compreensão dos processos erosivos naturais e acelerados nas teorias que fundamentam as analises dos processos geomorfológicos. Algumas das teorias que fundamentam estes processos são: Bioresistática (ERHART, 1956, apud CASSETI, 2001), Balanço Denudação (JANH, 1968 apud CASSETI, 2001) e Ecodinâmica (TRICART, 1977).

A teoria da Bioresistática de Erhart (1956) destaca a importância da cobertura vegetal para a manutenção do processo pedogenético. Ele ressalta com o termo de "biostasia" que somente as plantas atuam como fator de estabilização dos fluxos de radiação e das gotas da chuva e como moderadoras do vento. Assim, a vegetação é responsável pela proteção dos meios contra os processos morfogenéticos.

O Balanço Denudacional de Janh (1968) é outra teoria geomorfológica importante para a compreensão dos processos erosivos, visto que ela descreve a relação entre as componentes perpendiculares e paralelas e, dessa forma, tem com foco a evolução das vertentes por meio da atuação do processo erosivo.

Jean Tricart (1977) apresenta, em seu livro Ecodinâmica, uma análise dos meios em função da relação entre morfogênese e pedogênese, e classifica, desta forma, os meios como estáveis, em transição e instáveis. Conforme o proposto no livro Ecodinâmica, os meios estáveis são caracterizados pelo predomínio da pedogênese, ou seja, pela preponderância da formação de solo em relação à mor- 
fogênese, devido ao estado de clímax decorrente da cobertura vegetal que é considerada como fator de estabilidade. Em relação aos meios instáveis, o processo de morfogênese prevalece sobre o da pedogênese, isso ocorre devido à alteração sofrida pela paisagem, pois a vertente encontra-se em estado de instabilidade. Com ausência da cobertura vegetal tem-se que o escoamento superficial passa a ser predominante e consequentemente a erosão torna-se o processo responsável pela esculturação da vertente. Diante disso, a morfogênese passa a prevalecer em relação à pedogênese.

Apesar do processo de erosão ser algo natural e atuar na dinâmica de formação do relevo, o uso e a ocupação do solo podem acelerar esse processo, ou seja, o homem, como agente transformador de ambientes, atua na aceleração dos processos erosivos e, consequentemente, no ritmo de transformação da paisagem (FRANCISCO, 2011).

De acordo com Casseti (1991), o homem ao se apropriar e transformar a natureza, provocando significativas alterações no seu potencial ecológico, pode gerar um processo erosivo acelerado pela alteração do sistema hidrológico da vertente, gerando consequências irreversíveis.

\section{O PROCESSO EROSIVO ACELERADO PELAS AC̣ÕES ANTRÓPICAS}

Os sistemas ambientais naturais relacionados às intervenções humanas apresentam maior ou menor fragilidade em função das suas características genéticas. A princípio, os ambientes naturais em algumas regiões do planeta mostravam-se em estado de equilíbrio dinâmico até o momento em que as sociedades humanas passaram a intervir, progressivamente e mais intensamente, na apropriação dos recursos naturais (ROSS, 2000).

A crescente industrialização concentrada em cidades, a mecanização da agricultura nos sistemas de monocultura, a implantação de pastagens generalizadas e a intensa exploração dos recursos energéticos e das matérias-primas têm alterado o cenário da Terra e causado, com frequência, processos degenerativos profundos na natureza. Para Ross (2000), são necessárias duas condições básicas para que ocorram as regenerações espontâneas das águas, das coberturas vegetais, dos solos, da fauna e do relevo impactado de forma negativa pela ação antrópica. São elas, o tempo e a trégua, que dariam oportunidade de autorrecuperação e cessariam as intervenções altamente predatórias.

Os processos erosivos ocorrem naturalmente no meio ambiente, de forma lenta e gradual, causando, no decorrer da evolução do globo terrestre, mudanças no relevo e na vegetação (BERTONI; LOMBARDI NETO, 1990). A intervenção humana acelera esses processos erosivos por meio da ocupação e do uso intensivo 
do solo. A erosão antrópica, identificada como erosão acelerada, remove paulatinamente as camadas superficiais do solo, chegando a formar sulcos e ravinas, quando o escoamento da água é torrencial (CASSETI, 1991), influenciando diretamente na transformação das paisagens:

[...] em síntese, o homem ao apropriar-se da natureza e transformá-la pode processar alterações significativas na exploração biológica, gerando gradativamente modificações no potencial ecológico [...] A partir de então, altera-se o sistema hidrológico das vertentes, ou seja, o antigo domínio do componente perpendicular (infiltração) é substituído pelo paralelo (escoamento), evidenciando-se a implantação da erosão acelerada, o que pode gerar consequências irremediáveis se for ultrapassando o limiar de recuperação (CASSETI, 1991, p. 49).

O manejo do solo e as práticas tradicionais são as formas de intervenção que são responsáveis pela degradação dos solos, assim como a perda, devido às atividades antrópicas. $\mathrm{O}$ manejo do solo é medido pela cobertura de vegetação e do uso da terra.

Para Mafra (1999, p. 308): “[...] as perdas por erosão variam em intensidade de acordo com o uso da terra". A Figura 2 mostra, de forma ilustrada, a perda de solo referente a diferentes formas de uso da terra.

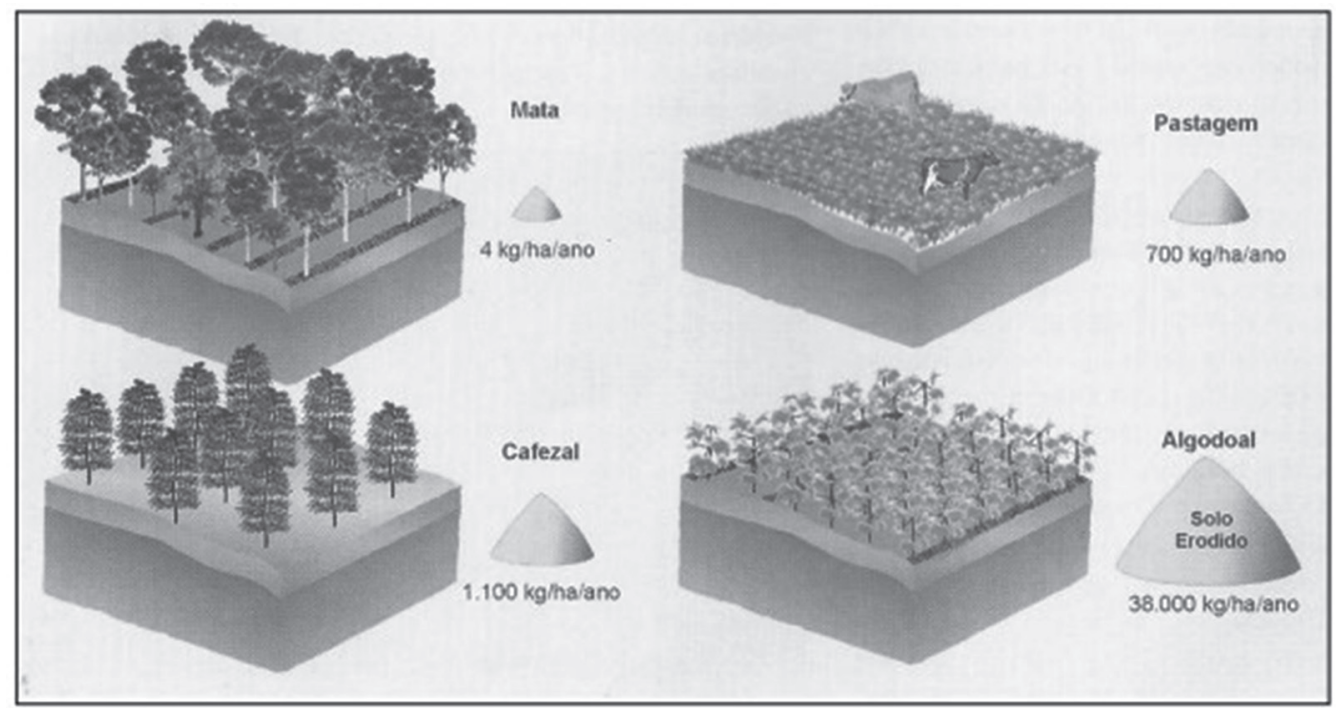

Figura 2. Comparação entre as perdas por erosão em relação ao uso do solo. Fonte: Lepsch (2002, p. 159).

A agricultura no Brasil, devido à abundância de terras e às exigências dos mercados internos e externos, vem incorporando gradativamente novas áreas para cultivo, principalmente para culturas tradicionais como a cana-de-açúcar e 
o café. É nesse contexto que acontecem a degradação física e o empobrecimento químico dos solos relacionados à erosão (MAFRA, 1999). Silva et al. (2005), em pesquisa realizada, demonstrou a intensificação de níveis críticos das feições erosivas em ambientes com pastagens e a necessidade de medidas conservacionistas.

Para Oliveira (1994), o processo histórico do uso do solo e as mudanças decorrentes dos processos erosivos acelerados contribuíram para a produção de sedimentos que foram transportados e depositados nos fundos de vale nas últimas décadas. Estes depósitos, denominados de tecnogênicos (CHEMEKOV, 1982 apud OLIVEIRA, 1994), são resultados da intensa atividade humana. Para Oliveira (1994, p. 4-5):

[...] o conceito abrange tanto os depósitos construídos, como os aterros de diversas espécies, quanto os depósitos induzidos, como os corpos aluvionares resultantes dos processos erosivos, desencadeados pelo uso do solo [...] a forma de ocorrência dos depósitos tecnogênicos também responde a um conjunto de técnicas de uso do solo, específico do estágio de evolução do homem, segundo as circunstâncias históricas da região considerada.

Sendo assim, os depósitos tecnogênicos "[...] contribuem para o conhecimento dos processos erosivos acelerados, através da reconstituição do passado do uso do solo" (OLIVEIRA, 1994, p. 208).

Um aspecto fundamental na compreensão da dinâmica do processo de voçorocamento, segundo Francisco (2011), é o histórico de transformação da paisagem, visto que, apesar de existirem algumas áreas que são naturalmente suscetíveis ao desenvolvimento de voçorocas, a maioria delas são induzidas pelas formas de uso e de ocupação do solo (OLIVEIRA, 1999).

Um fato evidente no aumento da frequência dos processos erosivos de voçorocamento é o aumento das áreas urbanas, principalmente em áreas de cabeceiras de drenagem e fundos de vale com ausência de planejamento e legislação adequa$\mathrm{da}$, acarretando sérios problemas de drenagem urbana, o que intensifica a ação da água sobre o solo. Durante a urbanização, os espaços permeáveis, inclusive áreas vegetadas e bosques, são convertidos em usos que, geralmente, provocam o aumento de áreas com a superfície impermeável, o que resulta no aumento do volume do escoamento superficial e da carga de poluentes (ARAUJO, 2012).

Conforme o processo de urbanização, começam a acontecer mudanças inevitáveis na hidrologia natural da área e na hidráulica, devido à limpeza do terreno, à terraplanagem e à adição de superfícies impermeáveis (SCHUELER apud ARAUJO, 2012). As superfícies impermeáveis, tais como telhados, ruas, estacionamentos, calçadas, diminuem a capacidade de infiltração do solo e resultam no aumento do escoamento superficial, conforme demonstra a Figura 3. 


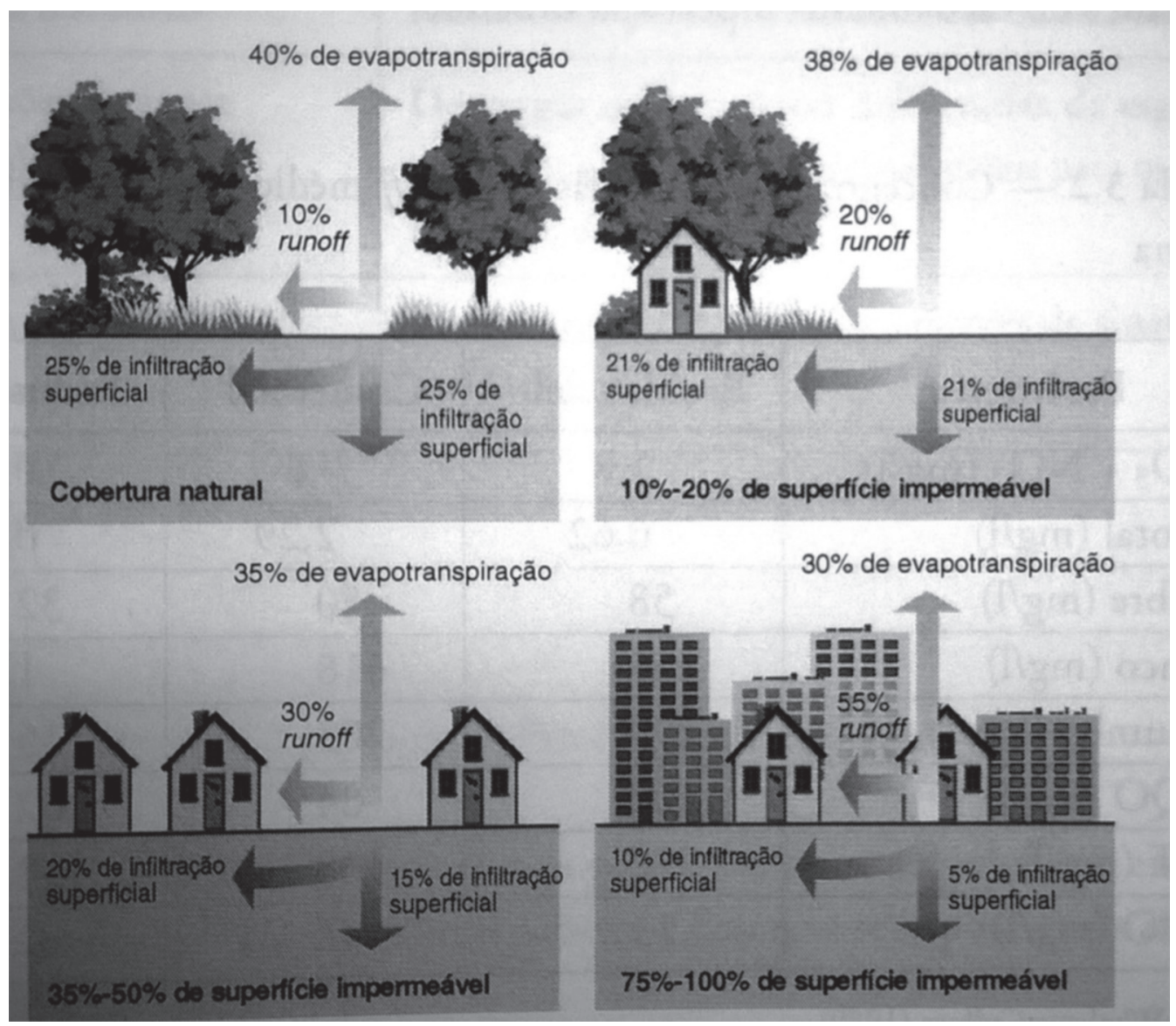

Figura 3. Relacionamento entre a superfície impermeável e o escoamento superficial. Fonte: Fisrwg (1998) apud Araujo (2012).

Tratando-se do Cerrado, Rodrigues (2014) salienta que são identificados vários fatores que, de forma isolada ou em conjunto, contribuem para a degradação e erosão dos solos desse bioma, como o desmatamento, a modificação das condições da cobertura vegetal, a compactação, o fogo, a alteração do nível de base local ou regional, as alterações estruturais na cobertura pedológica, entre outros.

Ainda segundo esse autor, o processo de desmatamento pelo qual o Cerrado vem passando desde o século XX converteu mais de $80 \%$ do ambiente original em áreas recobertas por pastagens e áreas cultivadas, além da silvicultura. Essas mudanças, então, geraram várias modificações na condição dos solos, dentre elas, a falta de proteção contra a ação direta das chuvas, a compactação do solo por máquinas ou gado, a utilização do fogo em queimadas de pastagens ou para abertura de novas áreas de exploração, resultando na diminuição da infiltração do solo e, consequentemente, no aumento do escoamento superficial, o que pode acelerar os processos erosivos. 


\section{ESTUDO DA DINÂMICA POR MEIO DO MONITORAMENTO DA FEIÇÃO E DA ANÁLISE DE SOLO}

É na etapa metodológica que o pesquisador delimita como será desenvolvida a pesquisa e, ainda, indica quais ferramentas serão utilizadas para se chegar às respostas. Para tanto, os resultados satisfatórios só serão possíveis com a intercalação das pesquisas teórica e de campo, que darão sustentação às discussões.

A proposta metodológica está centrada no método das estacas, proposta por Guerra (1996) e Francisco (2011), e análise do solo segundo o manual de métodos de análise da Embrapa (1997).

Com relação ao método de estaqueamento, Guerra (2005) considera que este procedimento metodológico é utilizado no monitoramento de erosão de borda em voçorocas. O mesmo autor diferencia as estacas utilizadas como referências na mensuração de erosão linear e os pinos de erosão que são utilizados "[...] para monitorar a perda de solos por erosão em lençol”. (GUERRA, 2005, p. 33)

$\mathrm{Na}$ proposta de monitoramento de voçorocas, Guerra (1996) salienta que se deve cravar as estacas no solo, ao redor da voçoroca, afastadas uma das outras cerca de $20 \mathrm{~m}$, mantendo um afastamento médio das bordas da voçoroca, como pode ser observado na Figura 4.

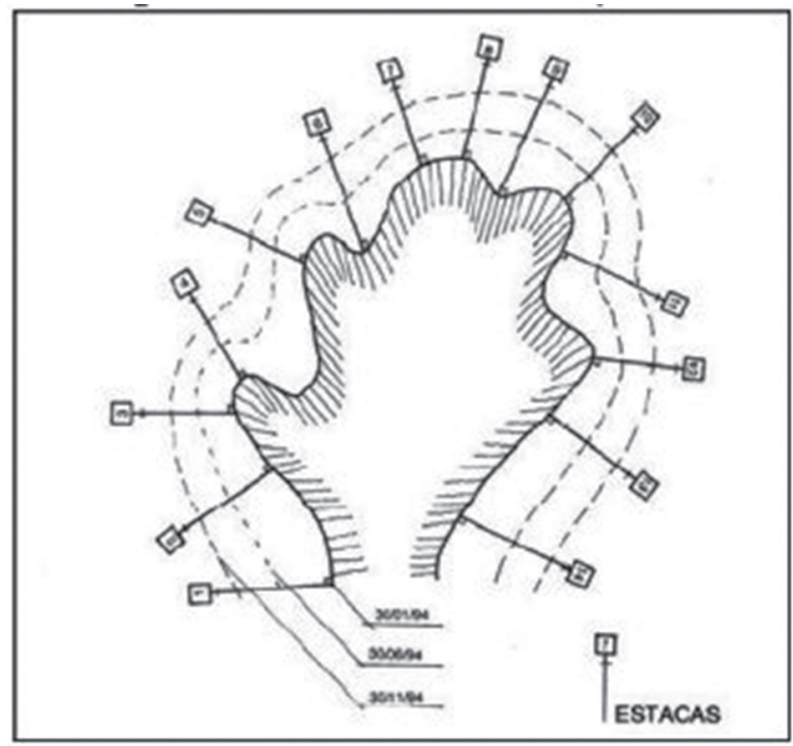

Figura 4. Monitoramento de voçoroca. Fonte: Guerra (1996, p. 144).

Para as estacas, é necessário também que existam níveis graduais com o intuito de medir a perda de solo pela erosão laminar (Figura 5), ou seja, essas esta- 
cas serão a referência para a medição nas taxas de erosão da borda da voçoroca como também para a erosão linear.

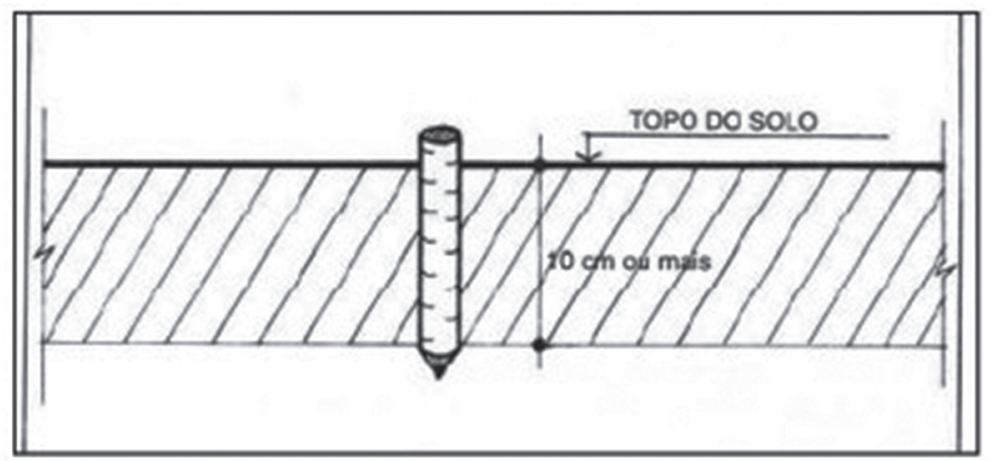

Figura 5. Estaca vista de perfil. Fonte: Guerra $(2002$, p. 151).

Além do monitoramento da borda da voçoroca pelo estaqueamento, será aplicada uma análise física do solo da voçoroca seguindo o manual de métodos de análise da Embrapa (1997).

Os pontos de coleta das amostras de solo serão escolhidos de acordo com as características dos solos observados em campo, como a cor e a textura. Após a escolha dos pontos, serão analisadas, ainda em campo, algumas características morfológicas dos perfis, como a espessura e arranjo dos horizontes.

Após essa análise morfológica, serão retiradas amostras dos horizontes para uma análise granulométrica, objetivando encontrar a porcentagem de areia, silte e argila. A partir dessas análises, será possível identificar o tipo de solo presente na área de estudo e discutir a sua susceptibilidade à erosão.

\section{CONSIDERAC̣ÕES FINAIS}

Diante do que foi explicitado, é preciso ficar claro que a metodologia aqui apresentada não é a única para o desenvolvimento de trabalhos ligados ao estudo das dinâmicas dos processos erosionais. Porém, a partir dos estudos e das leituras realizados, a metodologia se mostrou eficaz para os resultados esperados ao final de todo o trabalho.

É importante salientar que os estudos de processos erosivos são de grande importância para conhecer as dinâmicas do solo e propor formas de amenizar esses processos acelerados pela ação antrópica no meio. Diante do cenário de degradação dos solos pela erosão acelerada, considera-se a necessidade de estudos que visam não apenas à quantificação da perda de solos, mas também ao aprimoramento das técnicas de controle de erosão. 
Por fim, cabe destacar que esse trabalho se trata de um fragmento do pré-projeto de pesquisa submetido ao Programa de Pós-Graduação em Geografia ofertado pelo Instituto de Geografia da Universidade Federal de Goiás/Regional Catalão e que muitas contribuições ainda são esperadas para este estudo. Sendo assim, por se tratar de uma pesquisa em andamento, ainda não é possível apresentar dados concretos sobre a dinâmica de voçorocamento na área urbana de Ituiutaba-MG, especificamente, da voçoroca localizada nos bairros Nova Ituiutaba.

\section{AGRADECIMENTOS}

À CAPES pela concessão de bolsa ao primeiro autor e ao Programa de Pós-Graduação em Geografia da Universidade Federal de Goiás - Regional Catalão.

\section{REFERÊNCIAS}

AB'SABER, A. N. As boçorocas de Franca. Revista da Faculdade de Filosofia, Ciências e Letras de Franca, Franca, v. 1, n. 2, 1968.

ABREU, M. L. Uso de modelos de circulação geral da atmosfera para simular o clima e a variabilidade climática. In: SANT'ANNA NETO, J. L.; AVATINI, J. A. Variabilidade e mudanças climáticas: implicações ambientais e socioeconômicas. Maringá: Eduem, 2000.

ARAUJO, G. H. S. Ambiente urbano e industrial. In: ARAUJO, G. H. S.; ALMEIDA, J. R.; GUERRA, A. J. T. Gestão ambiental de áreas degradadas. 8. ed. Rio de Janeiro: Bertrand Brasil, 2012.

AUGUSTIN, C. H. R. R.; ARANHA, P. R. A. Piping em área de voçorocamento, Noroeste de Minas Gerais. Revista Brasileira de Geomorfologia, São Paulo, v. 7, n. 1, 2006.

BACCARO, C. A. D. As unidades geomorfológicas do Triângulo Mineiro. Sociedade e Natureza, Uberlândia, n. 5 e 6, p.37-42, jan.-dez., 1991.

BERTONI, J.; LOMBARDI NETO, F. Conservação do solo. 9. ed. São Paulo: Ícone, 1990. $355 \mathrm{p}$.

CASSETI, V. Ambiente e apropriação do relevo. São Paulo: Contexto, 1991.

Geomorfologia. Fundação de Apoio a Pesquisa - FUNAPE/UFG, 2001.

Disponível em: <www.funape.org.br/geomorfol>. Acesso em: 15 nov. 2014.

EMBRAPA. Centro Nacional de Pesquisa de Solos. Manual de métodos de análise de solos. 2. ed. rev. e atual. Rio de Janeiro: EMBRAPA, 1997. 212 p.

FRANCISCO, A. B. O processo de voçorocamento no perímetro urbano de Rancharia - SP: sua dinâmica e as propostas de recuperação. 2011. 124 f. Dissertação (Mestrado)

- Faculdade de Ciências e Tecnologia. Universidade Estadual Paulista, Presidente

Prudente, 2011.

FURLANI, G. M. As boçorocas de Casa Branca e seu significado geomorfológico.

Geomorfologia, Instituto de Geografia, Universidade de São Paulo, p. 12-15, 1980. 
FUSHIMI, M. Vulnerabilidade ambiental aos processos erosivos lineares nas áreas rurais do município de Presidente Prudente-SP. 2012. 142 f. Dissertação (Mestrado) - Faculdade de Ciências e Tecnologia, Universidade Estadual Paulista, Presidente Prudente, 2011.

GUERRA, A. J. T. O início do processo erosivo. In: GUERRA, A. J. T.; SILVA, A. S. da; BOTELHO, R. G. M. (Org.). Erosão e conservação dos solos: conceitos, temas e aplicações. Rio de Janeiro: Bertrand Brasil, 1999.

. Experimentos e monitoramentos em erosão dos solos. Revista do Departamento de Geografia, n. 16, p. 32-37, 2005.

GUERRA, A. J. T.; CUNHA, S. B. Geomorfologia: exercícios, técnicas e aplicações. Rio de Janeiro: Bertrand Brasil, 1996. 345 p.

LEPSCH, I. F. Formação e conservação do solo. São Paulo: Oficina de Textos, 2002.

MAFRA, N. M. C. Erosão e planificação de uso do solo. In: GUERRA, A. J. T.; SILVA, A. S.; BOTELHO, R. G. M. (Org.). Erosão e conservação dos solos: conceitos, temas e aplicações. Rio de Janeiro: Bertrand Brasil, 1999, p. 301-323.

OLIVEIRA, M. A. T. de. Processos erosivos e preservação de áreas de risco de erosão por Voçorocas. In: GUERRA, A. J. T.; SILVA, A. S. da; BOTELHO, R. G. M. (Org.). Erosão e conservação dos solos: conceitos, temas e aplicações. Rio de Janeiro: Bertrand Brasil, 1999.

OLIVEIRA, A. M. S. Depósitos tecnogênicos e assoreamento de reservatórios: exemplo do reservatório de Capivara, Rio Paranapanema, SP/PR. Tese (Doutorado em Geografia Física) - Faculdade de Filosofia, Letras e Ciências Humanas, Universidade de São Paulo, 1994.

RODRIGUES, S. C. Degradação dos solos do cerrado. In: GUERRA, A. J. T.; JORGE, M. C. O. (Org.). Degradação dos solos no Brasil. Rio de Janeiro: Bertrand Brasil, 2014. ROSS, J. L. S. Geomorfologia aplicada aos EIAs - RIMAs. In: GUERRA, A. J. T.; CUNHA, S. B. (Org.). Geomorfologia e meio ambiente. 3. ed. Rio de Janeiro: Bertrand Brasil, 2000. 372 p.

ROSSATO, M. S. et al. (Org.). Terra: feições ilustradas. Porto Alegre: Editora da Universidade Federal do Rio Grande do Sul, 2003.

SALOMÃO, F. X. T. Controle e prevenção dos processos erosivos. In: GUERRA, A. J. T.; SILVA, A. S.; BOTELHO, R. G. (Org.). Erosão e conservação dos solos: conceitos, temas e aplicações. Rio de Janeiro: Bertrand Brasil, 1999.

SILVA, A. M. da. et al. Estudo integrado do processo erosivo numa microbacia experimental localizada no município de Cunha - SP. Rev. Geociências, São Paulo (Universidade Estadual Paulista), v. 24, n. 1, p. 43-53, 2005.

SUGUIO, K. Dicionário de geologia sedimentar e áreas afins. Rio de Janeiro: Bertrand Brasil, 1998. 1.222 p.

TRICART, J. Ecodinâmica. Rio de Janeiro: IBGE, SUPREN, 1977. 91 p.

WEILL, M. de A. M.; NETO, A. G. P. Erosão e assoreamento. In: SANTOS, R. F. dos. (Org.). Vulnerabilidade Ambiental. Brasília: MMA, 2007. p. 39-58. 
